\section{Use of pulse crops in complementary feeding of 6-23-month-old infants and young children in Taba Kebele, Damot Gale District, Southern Ethiopia}

\author{
Addisalem Mesfin, ${ }^{1}$ Carol Henry, ${ }^{2}$ \\ Meron Girma, ${ }^{1}$ Susan J. Whiting ${ }^{2}$ \\ 1School of Food Science and Nutrition, \\ Hawassa University, Ethiopia; ${ }^{2}$ College of \\ Pharmacy and Nutrition, University of \\ Saskatchewan, Saskatoon, Canada
}

\section{Abstract}

Poor complementary feeding practices contribute to infants and young children (IYC) malnutrition, with lack of protein-containing food and micronutrients as major concerns. A cross-sectional survey was conducted to assess the dietary diversity, nutrient contents and use of pulse crops in complementary feeding at Taba kebele, Southern Ethiopia. A questionnaire was used to collect socio-demographic and dietary diversity data from a random sample of 128 mother-child pairs. A one day weighed food record assessed IYC median nutrient intake. Focus group discussion explored mothers' perceptions and use of pulse crops in complementary food preparation. Dietary diversity assessment found that $43.7 \%$ consumed pulses, and only $18.7 \%$ consumed meat and $26.6 \%$ eggs. Focus group discussion showed that mothers had little interest in incorporating pulses into complementary foods. Raising awareness of mothers/caregivers on food diversification and promoting the inclusion of pulses in food preparation for infants and young children are vital to nutritional status of IYC.

\section{Introduction}

The period from birth to two years of age is the critical period in which growth faltering and micronutrient deficiencies can occur. Nutritional vulnerability during this period results from poor breastfeeding and complementary feeding practices, coupled with high rates of infectious diseases. ${ }^{1}$ Guidelines developed for the introduction of complementary foods for breastfed infants and young children (IYC) between 6-23 months of age recommend that feeding should be timely, adequate, prepared and given in a safe manner, given in a way that is suitable, in the appropriate texture, and given in sufficient quantity. ${ }^{2}$ A Dietary Diversity Score at an individual's level reveals the nutrient adequacy of a diet. It is measured as being consumption by the child of at least four of seven foods food groups per day. The individual Dietary Diversity Score is related to increased nutrient adequacy of the diet, with scores being positively correlated with adequate micronutrient density of complementary foods for infants and young children. ${ }^{3}$

In 2005 Ethiopian national survey, except animal milk and dairy products only $6 \%$ IYC between 6-11 months received other animal source foods such as meat, fish, and poultry. Until family food is started usually cereal based gruel and porridges are given. ${ }^{4}$ The finding of a study conducted in two villages in predominantly cereal and root crop production areas of southern Ethiopia showed that the major complementary foods in the cereal production area were fenugreek water and thin cereal based gruel while in the root crop production area foods were boiled potatoes, corn bread or kocho bread. ${ }^{5}$

Along with macronutrients, leguminous seeds also contain appreciable amounts of some vitamins and minerals as well as dietary fiber. Legumes occupy an important place in human nutrition especially in the dietary pattern of low-income groups of people in developing countries. Those leguminous plants referred to as pulses include beans, lentils, dried peas, chickpeas and faba (or broad) beans. Pulses, considered as poor man's meat, are generally good sources of slow release carbohydrates and are rich in protein. ${ }^{6}$ It is critical that infants eat high quality and easily digestible proteins which can be provided by animal foods or by properly mixing cereals with pulses. ${ }^{7}$

A study conducted in southern Ethiopia, found that the protein concentration of a pulse-supplemented maize (Zea mays) and kocho (Enset ventricosum) complementary food improved by $60 \%$ compared with the traditional maize and kocho; ${ }^{8}$ however, the extent to which mothers and caregivers use pulses for complementary feeding is not known. The overall aim of this study was to assess complementary feeding practices of mothers in southern Ethiopia focusing on diet diversity and in particular the contribution of pulse crops in complementary food preparation of 6-23 month old IYC.

\section{Materials and Methods}

\section{Study area}

The study was conducted at Taba kebele, in the Southern Nations, Nationalities and
Correspondence: Carol Henry, College of Pharmacy and Nutrition, University of Saskatchewan, 110 Science Place, Saskatoon, SK S7N 5C9, Canada.

Tel.: +1.306.966.5833 - Fax: +1.306.966.6377.

E-mail: cj.henry@usask.ca

Key words: pulses; complementary feeding; dietary diversity.

Contributions: AM completed the research for her Masters in the Applied Nutrition degree; $\mathrm{CH}$ participated in the design, execution and manuscript preparation; MG, participated in the design, execution and manuscript preparation; SW, participated in the design of the study and in manuscript preparation.

Conflict of interest: the authors declare no potential conflict of interest.

Funding: Canadian International Food Security Research Fund (CIFSRF); International Development Research Centre (IDRC); Department of Foreign Affairs and Development Canada (now Global Affairs Canada).

Received for publication: 17 July 2013.

Revision received: 14 June 2014.

Accepted for publication: 11 June 2015.

This work is licensed under a Creative Commons Attribution NonCommercial 3.0 License (CC BYNC 3.0).

(C) Copyright A. Mesfin et al., 2015

Licensee PAGEPress, Italy

Journal of Public Health in Africa 2015; 6:357 doi:10.4081/jphia.2015.357

Peoples Region (SNNPR) Ethiopia. In 2011, the study area had a total population of 5074 (Sintayehu and Worku 2011, unpublished baseline survey), with 878 registered households (179 headed by women). The agro climatic zone of the kebele is $25 \%$ tropical (Kolla) and $75 \%$ subtropical (Woinadega). The major crops grown include potato (Solanum tuberosum), maize (Zea mays), haricot bean (Phaseolus vulgaris), teff (Eragrostis tef) and sweet potato (Ipomoea batatas).

\section{Study design}

A community based cross-sectional survey with both qualitative and quantitative components was used. The qualitative design encompasses questionnaires based interviews and weighed food records. The qualitative approach was addressed using Focus Group Discussion (FGD).

\section{Study population}

The study population was 6-23 months old IYC and their mothers were included in the study. 


\section{Sample size}

The sample size was computed using single proportion sample size calculation formula with the inputs of $95 \%$ confidence level, $5 \%$ margin of error, $50 \%$ expected prevalence. The formula was also corrected to finite source population size because the total study population was below 10,000 . Five percent of the sample was added for possible non response committed. Finally the total sample size calculated was 128. All the 128 were considered for the questionnaire based interview and half (64) were considered for the weighed food record

\section{Sampling technique}

The study area was selected purposively as baseline survey showed that the area is known for growing some pulses (Sintayehu and Worku 2011, unpublished baseline survey). For the interview 128 mothers who lived in the area for at least 6 months were selected. A simple random sampling technique was used to select mother- child pairs. First a house to house registration was conducted to identify households with IYC6-23 months old using their immunization card. During the registration, exclusive codes were given for each household.

A total of 189 IYC were found. Using the 189 list a sampling frame was prepared and then the 128 were drawn using a lottery method. For the weighed food record adequately half (64) subsample were selected out of the study population similarly by using lottery method. ${ }^{9}$

\section{Data collection procedure}

The data were collected from February to March, 2011. Prior to starting the work, the Ethical Review Committee of Hawassa University approved the study. The study objective was explained to officials of health and administrative departments of the study area for their permission and support. The nature of the study was fully explained to mothers/caregivers to obtain their oral consent. Three day training was given by the prin- cipal investigator for all data collectors who are diploma nurses fluent in the local language. A pre-test was undertaken on $5 \%$ of the sample size of the study participants outside of the chosen study area. Close supervision and checking for data completeness was done each day. Subjects were re-interviewed when issues related to non-responses were encountered.

\section{Dietary assessment}

To assess the quantitative aspect the foods consumed by IYC, a one day weighed food record was conducted on each randomly selected IYC ( $n=64)$ using digital scales ( $2 \mathrm{~kg}$ maximum weight: Model CS 2000, Ohaus Corporation, Newark, NJ, USA) with a precision of \pm 1.0 g. Mothers/caregivers were briefed not to change their usual dietary pattern on the food record day. The enumerators stayed in the selected household for the whole day and weighed each raw ingredients before cooking then all the foods after cooking and the amount served and leftovers for IYC. Four enumerators each conducted four records per a week by representing one weekend day, two week days and one market day proportionally. ${ }^{9}$ Mainly the nutrient content of the cooked foods were found using Ethiopian food composition tables, ${ }^{10,11}$ and Sidama food composition table. ${ }^{12}$ For few foods USDA food composition databases $^{13}$ and nutrient content of common Ethiopian foods ${ }^{14}$ were used with adjustment for differences in moisture contents. The qualitative aspect of the foods consumed by IYC was assessed using a one day dietary diversity recall on the 128 mothers. A separate food frequency questionnaire was used to assess the pulse consumption pattern. The common types of pulses grown in the area were listed and their consumption frequencies in a week, month and year were assessed accordingly.

\section{Focus group discussion}

The focus group discussions (FGDs) were conducted to explore attitudes and beliefs regarding incorporating pulses in complementary foods. After four sessions, data saturation occurred. There were a maximum of 11 mothers in each FGD. The participants were chosen if they had direct involvement in child care and complementary feeding decision making processes. Participants with similar age group and educational level were selected for each FGDs session. Two health extension workers who spoke the local language were recruited to serve as note takers. The FGDs were facilitated by the principal investigator. FGDs themes were explored using an interview guide.

\section{Data analysis}

The quantitative data were analyzed using SPSS version 16 (SPSS Inc., Chicago, IL, USA). Weighed food record data were analyzed using Food Processor (version 8.5). Estimated nutrient needs were used as cut off point to compare the nutrient intakes of children in different age groups. ${ }^{15}$

The nutrient density of the foods was calculated in a $100 \mathrm{kcal}$ of energy: median intake of nutrient of interest $\times 100 /$ median energy calculated.

Normality of weighed food record data was checked using Kolmogorov-Smirov test and most nutrients were not normally distributed so the result was described using median with Inter Quartile Range (IQR). Dietary Diversity was assessed based on WHO guideline of seven food groups: ${ }^{16}$ grains, roots and tubers; legumes (pulses) and nuts; vitamin-A rich fruits and vegetables; other fruits and vegetables; meat, chicken and fish; eggs; and milk and milk products.

Analyses of FGDs were performed by using the thematic analysis technique 17. Immediately after each FGD, the facilitator and note taker met to translate and transcribe the recorded discussions and written notes. The major themes coded by the principal investigator were availability of pulses, types of pulses consumed by IYC, barriers in pulse consumption by IYC and mother's perceptions in using pulses for preparing IYC foods and quotes of the participants were also generated to support these themes.

Table 1. Foods consumed by children 24 hours preceding the survey at Taba Kebele, Southern Ethiopia, 2011.

\begin{tabular}{|c|c|c|c|c|}
\hline Food groups & 6-8 months, n (\%) & 9-11 months, n (\%) & $12-23$ months, n (\%) & All children \\
\hline Grains, roots and tubers & $36(87.8)$ & $17(100)$ & $68(97.1)$ & $121(94.5)$ \\
\hline Legumes and nuts & $12(29.3)$ & $6(35.3)$ & $38(54.3)$ & $56(43.7)$ \\
\hline Vitamin-A rich fruits and vegetables & $18(43.9)$ & $8(47)$ & $42(60)$ & $68(53.1)$ \\
\hline Other fruits and vegetables & $15(36.6)$ & $13(76.5)$ & $61(87.1)$ & $89(69.5)$ \\
\hline Meat, chicken and fish & $5(12.2)$ & $4(23.5)$ & $15(21.4)$ & $24(18.7)$ \\
\hline Eggs & $11(26.8)$ & $3(17.6)$ & $20(28.6)$ & $34(26.6)$ \\
\hline Milk and milk products & $32(78)$ & $15(88.2)$ & $58(82.8)$ & $105(82)$ \\
\hline DDS (mean \pm SD) & $2.8 \pm 1.3$ & $3.2 \pm 1.2$ & $3.4 \pm 1.1$ & $3.1 \pm 1.2$ \\
\hline Total & 41 & 17 & 70 & 128 \\
\hline
\end{tabular}

DDS, dietary diversity score (food groups consumed). DDS should be $\geq 4$. 


\section{Results}

\section{Background characteristics}

Almost half (51.6\%) of the IYC were female and $48.4 \%$ were male. The average family size was seven. Of the mothers $78.1 \%$ were housewives. Half (49.2\%) of them had no formal education, $8.7 \%$ can read and write, $22.7 \%$ were within 1-6 grade and $19.4 \%$ were above grade six.

\section{Dietary diversity}

As shown in Table 1, meat and egg consumption was low. Almost all children consumed foods prepared from grains, roots and tubers, and the majority (82\%) also consumed milk. Of all the children, $43.7 \%$ consumed foods prepared from pulse crops and specifically 12-23-month-old children had slightly a higher consumption (54.3\%) than children in other age groups.

In the focus group discussions when moth- ers asked about what kind of complementary foods were common in the area, answers were varied. They reported common foods used were boiled egg, porridge, milk, beso roasted barley flour), leavened bread from the market, unleavened maize bread, kocho bread, boiled potato, bilindiwa (boiled kidney bean with cooked kocho), sweet potato and boyna (Colocasia esculenta), raw avocado, and kurkufa (maize dough and kale boiled together). However, they also said that children above one year of age usually consume family foods.

Table 2. Energy, nutrient, and phytate intake from foods consumed by infants and young children at Taba Kebele (n=64) compared to estimated needs.

\begin{tabular}{lccc} 
& $6-8$ months & $9-11$ months & $12-23$ months \\
Energy (kcal) & $350(304,434)$ & $462(377,565)$ & $447(361,678)$ \\
Estimated need & 202 & 307 & 548 \\
Protein (g) & $7.2(4.7,12.1)$ & $12.9(9.4,14.1)$ & $10.5(8.1,20.2)$ \\
Estimated need & 2 & 3.1 & 5 \\
\hline Calcium (mg) & $107(74,200)$ & $195(125,282)$ & $136(94,219)$ \\
Estimated need & 211 & 228 & 346 \\
Iron (m) & $5.9(4.4,11.6)$ & $12(6.4,19.5)$ & $8.6(6.9,13.9)$ \\
Estimated need & 18.4 & 18.4 & 11.4 \\
Zinc (m) & $3(1.9,4.8)$ & $5.2(3,1.2)$ & $4.5(2.2,6.8)$ \\
Estimated need & 7.6 & 7.7 & 7.6 \\
Thiamin (mg) & $0.11(0.07,0.26)$ & $0.16(0.10,0.20)$ & $0.14(0.10,0.30)$ \\
Estimated need & 0.16 & 0.17 & 0.38 \\
\hline Riboflavin (mg) & $0.29(0.17,0.59)$ & $0.60(0.40,1.10)$ & $0.30(0.10,0.60)$ \\
Estimated need & 0.16 & 0.18 & 0.31 \\
Niacin (mg) & $0.9(0.7,1.6)$ & $1.8(1.0,1.9)$ & $1.5(1.0,2.4)$ \\
Estimated need & 3.00 & 3.1 & 5.2 \\
\hline Vitamin C (mg) & $2.6(2.2,3.7)$ & $3.6(2.5,60)$ & $3.8(2.3,6.5)$ \\
Estimated need & 3.0 & 5.4 & 8.0 \\
Vitamin A (RE) & $184(15,415)$ & $224(61,479)$ & $90(32,541)$ \\
Estimated need & 63 & 92 & 126 \\
\hline Phytate (mg) & $397(98,570)$ & $448(109,890)$ & $480(188,780)$ \\
\hline
\end{tabular}

Median (25th and 75th percentile) nutrient intakes of complementary foods consumed by infants and young children which is computed from a one day weighed food record data: distributed in three age categories.

Table 3. Nutrient densities of foods consumed by infants and young children at Taba Kebele (n=64) compared to desired densities.

\begin{tabular}{|c|c|c|c|}
\hline & 6-8 months & 9-11 months & 12-23 months \\
\hline $\begin{array}{l}\text { Protein }(\mathrm{g} / 100 \mathrm{kcal}) \\
\text { Desired }\end{array}$ & $\begin{array}{c}2.06(1.34,3.57) \\
1\end{array}$ & $\begin{array}{c}2.80(2.03,3.05) \\
1\end{array}$ & $\begin{array}{c}2.34(1.81,4.52) \\
0.9\end{array}$ \\
\hline $\begin{array}{l}\text { Calcium }(\mathrm{mg} / 100 \mathrm{kcal}) \\
\text { Desired }\end{array}$ & $\begin{array}{c}30.6(21.3,57.1) \\
105\end{array}$ & $\begin{array}{c}29.2(27.0,61.0) \\
74\end{array}$ & $\begin{array}{c}30.5(20.9,196.1) \\
63\end{array}$ \\
\hline $\begin{array}{l}\text { Iron }(\mathrm{mg} / 100 \mathrm{kcal}) \\
\text { Desired }\end{array}$ & $\begin{array}{c}1.68(1.26,3.31) \\
9.1\end{array}$ & $\begin{array}{c}2.61(1.38,4.22) \\
6.0\end{array}$ & $\begin{array}{c}1.92(1.54,3.11) \\
2.1\end{array}$ \\
\hline $\begin{array}{l}\text { Zinc }(\mathrm{mg} / 100 \mathrm{kcal}) \\
\text { Desired }\end{array}$ & $\begin{array}{c}0.86(0.54,1.37) \\
3.8\end{array}$ & $\begin{array}{c}1.25(0.67,1.36) \\
2.5\end{array}$ & $\begin{array}{c}1(0.49,1.52) \\
1.4\end{array}$ \\
\hline $\begin{array}{l}\text { Thiamin }(\mathrm{mg} / 100 \mathrm{kcal}) \\
\text { Desired }\end{array}$ & $\begin{array}{c}0.03(0.02,0.07) \\
0.08\end{array}$ & $\begin{array}{l}0.03(0.02,0.04) \\
0.06\end{array}$ & $\begin{array}{c}0.03(0.02,0.07) \\
0.07\end{array}$ \\
\hline $\begin{array}{l}\text { Riboflavin }(\mathrm{mg} / 100 \mathrm{kcal}) \\
\text { Desired }\end{array}$ & $\begin{array}{c}0.08(0.05,0.17) \\
0.08\end{array}$ & $\begin{array}{c}0.13(0.08,0.23) \\
0.06\end{array}$ & $\begin{array}{c}0.06(0.02,0.13) \\
0.06\end{array}$ \\
\hline $\begin{array}{l}\text { Niacin }(\mathrm{mg} / 100 \mathrm{kcal}) \\
\text { Desired }\end{array}$ & $\begin{array}{c}0.26(0.2,0.46) \\
1.5\end{array}$ & $\begin{array}{c}0.39(0.22,0.41) \\
1.0\end{array}$ & $\begin{array}{c}0.33(0.22,0.54) \\
0.9\end{array}$ \\
\hline $\begin{array}{l}\text { Vitamin C }(\mathrm{mg} / 100 \mathrm{kcal}) \\
\text { Desired }\end{array}$ & $\begin{array}{c}0.74(0.63,1.05) \\
1.5\end{array}$ & $\begin{array}{c}0.78(0.54,1.31) \\
1.7\end{array}$ & $\begin{array}{c}0.85(0.51,1.45) \\
1.5\end{array}$ \\
\hline Vitamin A (RE/100 Kcal) & $52.6(4.28,118.6)$ & $64(17.4,136.8)$ & $25.7(9.1,154.6)$ \\
\hline Desired & 31 & 30 & 23 \\
\hline
\end{tabular}

Median $\left(25^{\text {th }}\right.$ and $75^{\text {th }}$ percentile) energy and nutrient intakes of infants and young children from complementary foods computed from a one day weighed food record data: distributed in three age categories. 
Most participants frequently mentioned that except kidney bean, other pulses were not common for preparation of complementary foods. Importantly, they said that the most common staple food item available as a food for children throughout the year is kocho, which is comprised of starch. In addition, mothers reported that they wished to have meat, egg, cheese in order to feed their children but these foods were too expensive and most households did not own livestock.

\section{Nutrient intakes}

Table 2 and 3 shows the median nutrient intakes and their densities in the IYC foods consumed. The median intake and density of protein was above the recommendation for all study IYC; the median energy and vitamin A intakes were above the estimated need for 6 11 months old and only riboflavin need was met for all. The median intakes of other key nutrients such as vitamin $\mathrm{C}$, iron, zinc, and calcium, were below the estimated needs; high phytate was consumed by $12-23$ month children

\section{Consumption frequency of com- mon pulses by infants and young children}

Most mothers responded they never used soybean or lentil for complementary food preparations (Figure 1). One fourth of mothers indicated that they had no practice of using broad bean, haricot bean, kidney bean, pea, and chickpea in complementary food preparations. Nearly one third of mothers reported they used broad bean, haricot bean, kidney bean, pea, chickpea and lentil twice or less per month but a bit lower consumption of soybean (19.5\%). Only few mothers said that they use pulses once or more per day. Regarding the consumption frequency of common pulses in a week, a small number of mothers reported using these pulses once, twice or 3-6 times per week. Pea, chickpea, kidney bean and broad bean were reported with a relatively better consumption pattern but soybean and lentil were reported as least consumed.
In the focus group discussions regarding pulse use, most mothers knew that there was a kidney bean (Phaseolus vulgaris) harvest twice per year and that it was the most available pulse. They usually used this pulse, boiled, with cooked enset, to prepare a local food called bilindiwa which was mainly consumed by older children. One lady also said $I$ used to give boiled haricot bean for my young child as snack.

Chickpea is available only once per year and also they reported that lentil and pea do not grow in the area. During the discussion mothers also mentioned some of the barriers of pulse consumption. Haricot bean consumption was varied because it did not usually grow well each year in the area. Chickpea was usually roasted (locally called kollo), thus not suitable for young children. Mothers further mentioned they did not usually use lentil and peas to prepare complementary foods because they did not regularly grow in the area so they had to buy them from the local market. One lady said if we got pea and lentil, why not? We give pea and lentil stew for the older children.
The result from the FGD regarding the nutritional importance of pulses shows that answers were consistent among all respondents that they do not have any knowledge about the nutritional importance of pulses and due to this very reason they do not give any special attention for pulses. All of the mothers agreed that they use pulses to prepare foods for children only when it is available at home. When mothers were asked to describe foods they preferred and considered as important to feed for children some of the food items mentioned by nearly all participants were barley with oat gruel, cheese, butter and egg.

\section{Discussion}

Though a $24 \mathrm{hr}$ recall cannot appropriately reveal the actual quality of the diet because of possible variations from one day to another, ${ }^{18}$ but still dietary diversity score can be considered a good proxy in assessing the global quality of IYC foods. ${ }^{19}$

In this study within $24 \mathrm{hr}$, only few IYC con-

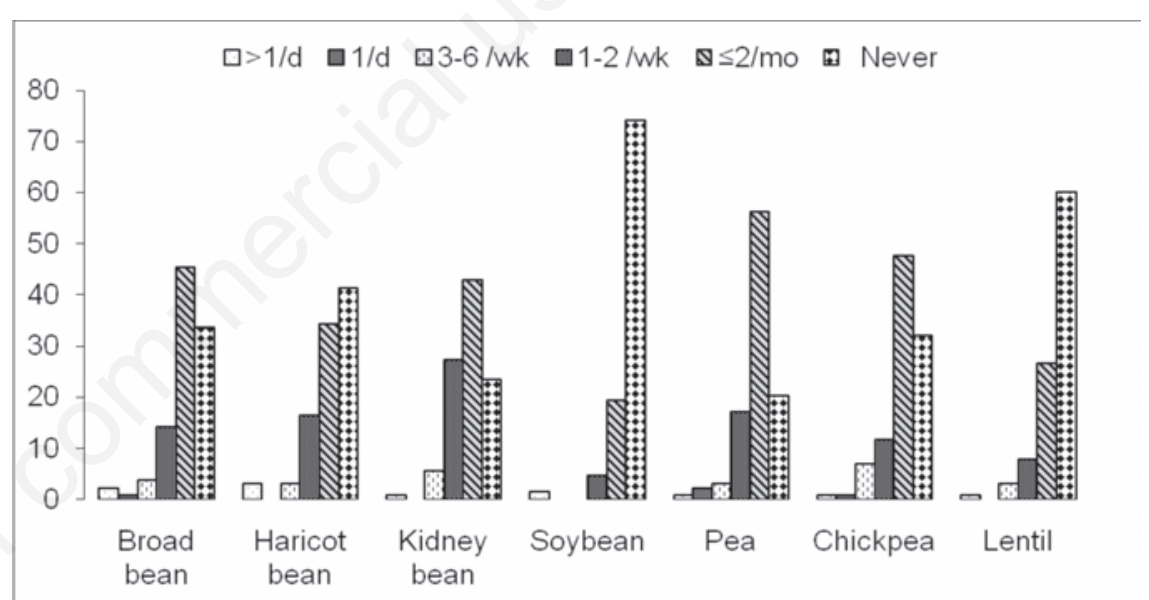

Figure 1. Consumption frequency of common pulses in percentage by Infants and Young Children at Taba Kebele, Ethiopia $(n=128)$. Data from a Food Frequency Questionnaire showing Infants and Young Children common pulse crops consumption in a day, week and month period or who never consumed pulses.

Table 4. Contribution of pulses and other food groups for protein intake of infants and young children at Taba kebele, 2011 (n=64).

\begin{tabular}{|c|c|c|c|}
\hline & 6-8 months & 9-11 months & 12-23 months \\
\hline Cereals & 34.1 & 52.8 & 25.6 \\
\hline Roots and tubers & 39.6 & 5.8 & 56.4 \\
\hline Legumes/pulses & 0.7 & 3.4 & 3.1 \\
\hline Milk and milk products & 21.4 & 33.3 & 11.9 \\
\hline Vegetables & 3.2 & 2.2 & 1.5 \\
\hline Fruits & 0.6 & 0 & 0.6 \\
\hline Egg & 1.6 & 0 & 0 \\
\hline Beverages & 0.6 & 2.4 & 0.8 \\
\hline
\end{tabular}

The median Infants and Young Children protein intakes contributed by pulses and other food groups computed from a one day weighed food record data: described in percentage. 
sumed meat and egg and almost all IYC consumed foods prepared from grains, roots and tubers. Generally the mean dietary diversity score is $3.1 \pm 1.2$ out of seven food groups. This is consistent with previous study report in southern Ethiopia which the diets consumed by $6-23$ months IYC were monotonous with low dietary diversity. Pieces of unmashed maize bread was the main complementary food consumed, even by infants as young as 6 to 8 months. ${ }^{15}$ It is also in line with the 2005 Ethiopian DHS survey result on IYC 6-23 months that found the proportion who consumed foods made from grains was $70 \%$ which is the highest compared with the consumption of other types of solid or semisolid foods. For instance, at age 6-23 months, only $10 \%$ of children were reported to consume meat, fish, egg. ${ }^{4}$ Studies in other developing countries like Somalia also prove that lack of dietary variety is typical where children are mainly fed a cereal based diet, ${ }^{20}$ and in Kenya that at least $60 \%$ of the children consumed starchy staples, oils and the dietary diversity were limited in animal products as well as pulse crops. ${ }^{21}$ The possible reason could be that animal source foods are expensive. Further meat is perceived not be to be well tolerated by IYC as evidenced in a case study done in Ethiopia and other countries which showed beside the cost of animal source foods the Ethiopia case study shows caregivers' perceptions, cultural norms and religious taboos of giving any or specific animal source foods to children and the fact that animal-source foods are primarily consumed on special occasions are the factors. At least half of the children 6 to 23 months of age in the Mexico, Peru, Haiti, and Senegal case studies had consumed an animal-source food in the previous day, whereas $27 \%$ to $51 \%$ of Ethiopian children under 36 months of age in the case study had consumed an animalsource food in the same period..$^{22}$ The median intake and density of protein was above the recommendation for all the study IYC (Tables 3 and 4). The protein intake, while meeting requirements, was from foods of poor protein quality, and there was no evidence of combining grains with pulses. The median energy and vitamin A intakes were above the estimated need for 6-11 months old but the energy intake was below the requirements for children 12-23 months old (Table 2). Low intake of energy for this age group could be due to the decrease in breast feeding and caring practices as children get older, and also as older children shift to eat family foods though other studies are in contrast that energy intakes from complementary foods was also inadequate for 6-11 IYC. .5,23,24 $^{2}$ Only riboflavin need was met for all but the median intakes of other key nutrients such as vitamin $\mathrm{C}$, iron, zinc, and calcium, were below the estimated needs for all IYC. Low intakes of key micronutrients in the study area were like- ly related to low consumption of animal foods and fruits and vegetables. A study done in North Wollo, Ethiopia on children aged 12-24 months provided evidence that, except Fe and protein, energy and other nutrient intakes were far below WHO recommendations. ${ }^{25} \mathrm{~A}$ similar result is also found in a study at rural Sidama, Ethiopia, that showed with the exception of protein, the densities of most nutrients such as calcium, thiamin, riboflavin, vitamin C, vitamin A were less than $80 \%$ of the desired level. ${ }^{15}$ A study in northern Ethiopia also showed energy and nutrient density of the complementary foods were low as the foods were prepared from a limited number of local staple cereals without the addition of fat/oil or animal products. More importantly, these foods are diluted with water to reduce their viscosity. This makes the quality and quantity of the foods insufficient. ${ }^{26}$ Furthermore the study showed that most diets given to children had high phytate and low micronutrient densities. Studies have shown that high phytate and low micronutrient density in the diet interferes with nutrient absorption and may further lead to malnutrition. ${ }^{2}$ As plant based complementary feeding patterns pose a strong risk, inclusion of meat as an early complementary food should be encouraged to meet micronutrient requirements. ${ }^{28}$ of all the children, $43.7 \%$ consumed foods prepared from pulse crops and specifically 12-23 months old children had slightly a higher consumption (54.3\%) than children in other age groups. In the FGD most participants frequently mentioned that except kidney bean, other pulses were not common for preparation of complementary foods. The most common food item available as a food for children throughout the year is kocho. Pulses were for older children. There were few recipes available as also mother don't have knowledge about the nutritional importance of pulses. In addition there is no large scale production of pulses, pulses too are relatively expensive. Further pulses are also perceived not be to be well tolerated by IYC.

\section{Conclusions}

In the study area foods given for infants and young children were monotonous which were dominant in cereal, roots and tubers and except milk lacks other animal source foods. These further reflected as low consumption of important micronutrients with low densities. Pulse crop consumption by children was minimal, even if it is a pulse growing area. Besides, mothers expressed that they do not give special attention to utilizing pulse crops in complementary foods. Furthermore the foods have low micronutrient densities.

Creating awareness in mothers/caregivers on how to diversify and prepare complementary foods for IYC from locally available nutrient dense animal and plant source food items, including promotion about the nutritional importance of pulses in the study area, is crucial.

\section{References}

1. Saha KK, Frongillo AE, Alam SD, et al. Appropriate infant feeding practices result in better growth of infants and young children in rural Bangladesh. Am J Clin Nutr 2008;87:1842-59.

2. Pan American Health Organization, World Health Organization. Guiding principles for complementary feeding of breastfed child. Washington DC: Division of Health Promotion and Protection/Food and Nutrition Program; 2003. pp 7-28.

3. Food and Nutrition Technical Assistance. Developing and validating simple indicators of dietary quality and energy intake of infants and young children in developing countries: summary of findings from analysis of 10 data sets. Working Group on Infant and Young Child Feeding Indicators. FANTA Project, Academy for Educational Development (AED), Washington, D.C. 2006.

4. Central Statistical Agency. Ethiopian demographic and health survey. available frm: http://www.dhsprogram. com/pubs/pdf /FR118/FR118.pdf.

5. Bogale A, Abebe Y. Child feeding practices and growth of infants and young children from two rural areas in southern Ethiopia. FASEB J 2006;20:A1049.

6. Tharanathan RN, Mahadevammaa S. Grain legumes: a boon to human nutrition. Trends Food Sci Technol 2003;14:507-18.

7. Cameron M, Hofvander Y. Manual on feeding infants and young children. 3rd ed. Oxford: Oxford University Press; 1983.

8. Abebe Y, Stoecker B, Hinds MJ, et al. Nutritive value and sensory acceptability of corn and Kocho based foods supplemented with legumes for infant feeding in southern Ethiopia. J Food Agriculture Nutr Develop 2006;6:4-11.

9. Gibson RS. Principles of nutritional assessment. 2 $2^{\text {nd }}$ ed. New York: Oxford University Press; 2005.

10. Ethiopian Nutrition Institute. Expanded food composition table for use in Ethiopia. Addis Ababa: Ethiopian Nutrition Institute; 1981. pp 1-32.

11. Ethiopian Health and Nutrition Research Institute. Food composition table for use in Ethiopia. Part IV. 1995-1997. Addis Ababa: Ethiopia Health and Nutrition Research Unit/Food and Agriculture Organization; 1998. pp 1-32. 
12. Abebe Y, Bogale A, Hambidge MK, et al. Phytate, zinc, iron and calcium content of selected raw and prepared foods consumed and implications for bioavailability in rural Sidama, southern Ethiopia. J Food Comp Anal 2007;20:161-8.

13. United States Department of Agriculture. National nutrient database for standard reference. Release 16. Washington: Nutrient Data Laboratory; US Government Printing Office; 2003.

14. Umeta M, West EC, Fufa H. Content of zinc, iron, calcium and inhibitors of their absorption in foods commonly consumed in rural Ethiopia. J Food Comp Anal 2003;18:803-17.

15. Gibson RS, Abebe Y, Hambidge MK, et al. Inadequate feeding practices and impaired growth among children from subsistence farming households in Sidama, southern Ethiopia. J Maternal Child Nutr 2009;5:260-75.

16. WHO. Indicators for assessing infants and young child feeding practices. Conclusions of a consensus meeting held 6-8 November in Washington, DC, USA. 2007.

17 USAID. Guide to focus group discussion. Micro report No 138.December 2008.

18. Piwoz EG. Improving feeding practices during childhood illness and convalescence: lessons learned in Africa. Washington, DC: Academy for Educational Development; 1994.

19. Moursi MM, Arimond M, Dewey KG, et al. Dietary diversity is a good predictor of the micronutrient density of the diet of 6 to 23 month-old children in Madagascar. J Nutr 2008;138:2448-53.

20. Mwaura W, Moloney G. Somali knowledge, attitude and practice study on infant and young child feeding and health seeking practices. United Nations Food and Agricultural Organization/Food Security Analysis. 2007. Unit 36-61.

21. Macharia-Mutie CW, Brouwer ID, Mwangi AM, Kok FJ.Complementary feeding practices and dietary intake among children 12-23 months in Mwingi District of Kenya. Int J Food Safety Publ Hlth 2010;3:45-56.

22. Helena $P$, Kirsten $B$, Safiètou $T$, et al. Constraints on the delivery of animalsource foods to infants and young children: case studies from five countries. Food Nutr Bull 2007;28:215-29.

23. Lakshmi AJ, Khyrunnisa B, Saraswathi G, Jamuna P. Dietary adequacy of Indian rural preschool children-influencing factors. Department of Studies in Food
Science and Nutrition, University of Mysore, Manasagangotri, India. J Trop Pediatr 2004;51:40-4.

24. Owino V0, Amadi B, Sinkala M, et al. Complementary feeding practices and nutrient intake from habitual complementary foods of infants and children aged 618 months old in Lusaka, Zambia. Afr J Food Agric Nutr Dev 2008;8:28-47.

25. Baye K, Guyot JP, Verniere CI, Rivier CM. Nutrient intakes from complementary foods consumed by young children (aged 12-23 months) from North Wollo, northern Ethiopia: the need for agro-ecologically adapted interventions. Public Health Nutr 2012;13:1-10.

26. Mulugeta A, Hagos F, Kruseman G, et al. Child malnutrition in Tigray, northern Ethiopia. East Afr Med J 2010;87:248-54.

27. Hurrell RF. Influence of vegetable protein sources on trace element and mineral bioavailability. J Nutr 2003;133:2973-7.

28. Krebs FN, Hambridge MK. Complementary feeding: clinically relevant factors affecting timing and composition: factors affecting complementary feeding. J Clin Nutr 2007;85:S639-45. 